\title{
Chapter 2 \\ Tokyo University of Agriculture East Japan Assistance Project Assisting with Reconstruction: Guiding Principles, Planning, and Propagation of Benefits
}

\author{
Toshiyuki Monma
}

\begin{abstract}
The Tokyo University of Agriculture East Japan Assistance project was started in April 2011 with Soma City, Fukushima Prefecture, as a target area. Three years having already elapsed since the start of the project, in the tsunami-affected areas, we contributed reconstruction in the tsunami damage paddy field by development and dissemination of restoration technology by the Tokyo University of Agriculture method and support of new farming organization construction. In addition, in the radioactive contamination area, we contributed clarification of the actual situation of radioactive contamination, and the decontamination method of the forest, and could restart farming by development of the radioactivity monitoring system.
\end{abstract}

Keywords Tokyo University of Agriculture - East Japan Assistance project

- Tsunami damage $\bullet$ Radioactive contamination

\subsection{The Launch of the East Japan Assistance Project}

\subsubsection{Initiatives to Support Disaster Zones and Students Affected by the Disasters}

The Great East Japan Earthquake struck 18.1 s after 2:46 p.m. on March 11, 2011, and it ranks among the most devastating disasters ever recorded anywhere in the world. The following morning, at Tokyo University of Agriculture, we focused all our efforts on checking for earthquake damage to our classrooms, laboratories, and other facilities, and on establishing which of our students had been affected by the

\footnotetext{
T. Monma $(\bowtie)$

Department of International Biobusiness Studies, Tokyo University of Agriculture,

1-1-1 Sakuragaoka, Setagaya-ku, Tokyo 156-8502, Japan

e-mail: monma@nodai.ac.jp
} 
earthquake and tsunami. We moved as quickly as we could to gather information about how our students had been affected, covering each faculty, department, and research group one by one. By March 31, we had completed our final checks on the safety of students whose homes were in the areas designated by the government as disaster zones (spread across the prefectures of Aomori, Iwate, Miyagi, Fukushima, Niigata, Ibaraki, Tochigi, Chiba, and Nagano). We established that 9 of our students had parents who were missing, 5 had other family members who were missing, 12 were in evacuation centers, 7 had lost their homes, and 21 had homes that were damaged.

We also considered the need for concrete measures to provide financial aid to those who required it among the 335 students from the government-designated disaster zones scheduled to start at the university in April, or among the 1,401 students from the disaster zones already enrolled at the university, and identified 204 students requiring aid. Specific aid measures included reducing or waiving tuition fees and subsidizing living expenses. Actual financial aid provided came to approximately 200 million yen in the academic year from April 2011 and 110 million yen in the academic year from April 2012.

\subsubsection{Our Desire to Help the Regions That Had Sustained Tsunami Damage and Radioactive Contamination, and the Launch of the Project}

Once the plans for providing aid to students had taken shape, we became aware of a rising groundswell of opinion among teaching staff and students who were saying that we should do something on behalf of the university to assist people in the disaster zones, or that they personally wanted to do what they could to help. The students in particular were saying that they wanted to work as volunteers to help people in the disaster-stricken areas. Meanwhile, teaching staff were saying that we as a university should do something to help revive the agriculture, forestry, and fishery industries in those areas, both to help with restoration and recovery and for the sake of the many students at the university who had suffered as a result of the disasters. Hearing this, the university authorities promptly embarked on a project to offer practical assistance for recovery in the disaster zones by drawing on the body of agricultural research amassed by the university. Overall guidance was provided by the former president of the university, Kanju Ohsawa (currently chairman of the board for the educational corporation that operates Tokyo University of Agriculture and its associated schools), and I was appointed project leader. I was in hospital at the time, but while I was confined to my sickbed I worked out what the project would entail, the organizational structure for undertaking research, and the fields to be researched. I then drew up an overall strategy for providing research-based 
assistance in the disaster zones and submitted it all to the university authorities. The project plan was deliberated first by the council of faculty heads, then by the university council, as a result of which an annual budget of 18 million yen was secured from internal funds and a decision was made to put the plan into action. The project was named the Tokyo University of Agriculture East Japan Assistance Project.

\subsection{The East Japan Assistance Project Gets Under Way}

\subsubsection{Why Soma Was Chosen for the Project}

There were a number of reasons why Tokyo University of Agriculture decided to start its postdisaster reconstruction project in the city of Soma. The Great East Japan Earthquake was a multiple disaster without precedent: in addition to an earthquake and tsunami, phenomena the Japanese people had experienced before, a new, completely unheard-of disaster was added in the form of radioactive contamination, and that in turn triggered further problems from reputational damage. The key factor in our choice of location, therefore, was our shared understanding that to achieve a genuine recovery following the Great East Japan Earthquake it would be essential to develop and promote technologies and methods designed to address four separate issues: the earthquake, the tsunami, the radioactive contamination, and the reputational damage.

Furthermore, the Tokyo University of Agriculture's educational philosophy is founded on a practical-science-based ethos, the essence of which is expressed in the words of the university's first president, Tokiyoshi Yokoi, who exhorted students of agriculture to "Ask the rice plant about the rice plant; ask farmers about agriculture." Adhering to this philosophy would therefore mean identifying the issues on site, developing scientific technologies and methods to resolve those issues, and conducting trials to demonstrate the efficacy of the technologies and methods, again on site. Our second shared understanding, therefore, was our commitment to maintaining a practical-science-based ethos from beginning to end as we undertook the East Japan Assistance Project.

We then added two more conditions to the factors already detailed: (a) our target disaster zone should not be closed to public access; and (b) there should be no prohibitions on planting crops, etc.

Having reduced the number of potential target sites for the assistance project by means of the foregoing conditions, we were left with the cities of Soma and Minamisoma as our two final candidate locations. Right up until the last minute we were torn between these two, but in the end we decided on Soma because it had no restrictions on planting paddy rice. 


\subsubsection{The First Comprehensive Surveys and the Initial Shock}

In getting the East Japan Assistance Project off the ground, the first major issue was how to forge a common understanding among the project team members about what they needed to do, what it was possible to do, and how it would be done. So we followed the maxim "seeing is believing," and visited Soma from May 1 to 4 to fully experience the extent of the damage there for ourselves. Once there, we held meetings with the Fukushima Agricultural Technology Centre's Hama District Research Institute and the city authority to discuss how the project would be implemented, and conducted surveys of the area. The group comprised the former president of Tokyo University of Agriculture, Kanju Ohsawa (who was still president at the time), myself as project leader, 12 members of the teaching staff, and two researchers. While conducting our on-site surveys we reached agreement with the relevant organizations on the details of how we would cooperate with them to implement the assistance project.

\subsubsection{Research Collaboration with Fukushima Prefecture}

A meeting was held at the Fukushima Agricultural Technology Centre's Hama District Research Institute in Soma to discuss our cooperation with Fukushima as a prefecture. It was confirmed that we would cooperate with the Hama District Research Institute on research to develop technologies to overcome the damage caused to fields by the incursion of seawater, earth, and sand. Meanwhile, we would also cooperate with the Fukushima Agricultural Technology Centre itself on research to ascertain the extent of damage to the region's farming and agricultural production structures and to investigate measures to provide assistance.

\subsubsection{Soma's Challenges and the University's Initiatives}

In our meeting with Soma's city authority, the mayor, Hidekiyo Tachiya, asked for our help with recovering the following agricultural issues: (a) identifying which of the approximately 1,100 ha of paddy fields covered in sludge and debris by the tsunami could be recovered and used again, and which could not; (b) investigating what specific measures should be taken to revive agriculture and farming villages; (c) investigating measures to deal with reputational damage now that the adverse effects resulting from radioactive contamination were lasting longer and becoming more serious than initially anticipated.

\subsubsection{Shock During Our On-Site Surveys}

Our on-site surveys involved inspecting the districts that had suffered particularly serious damage, guided by local residents who were assisting with the project. We had all to some extent formed our own impression of the aftermath of the disasters 

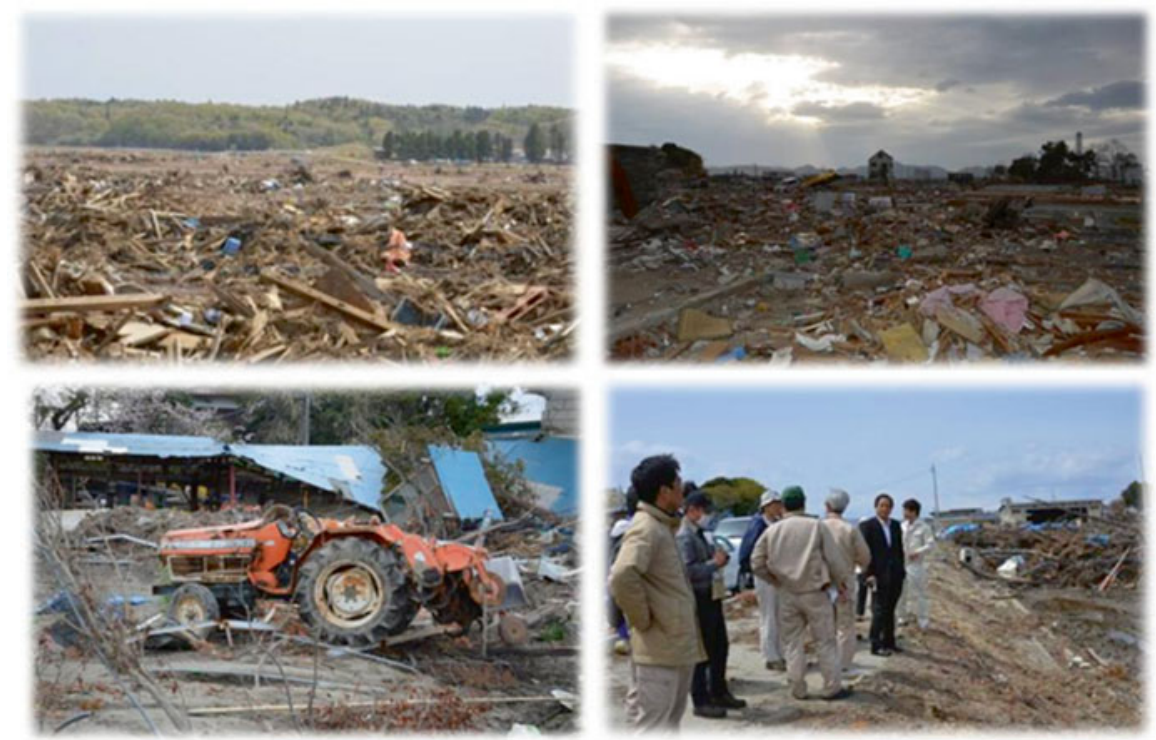

Fig. 2.1 Dumbfounded at the utter devastation wrought by the tsunami

from what we had seen and heard on the television and in newspapers. Nonetheless, when we saw with our own eyes what had actually happened there, the utter devastation wrought by the tsunami left us all dumbfounded. We wondered whether these districts really could be revived, whether there was actually anything we could do to help, whether the farmers would ever be able to recover from this (Fig. 2.1). But, shocked as they were, the teaching staff immediately started collecting soil samples, investigating how the disaster-stricken communities had been affected, and interviewing farmers about the damage to their farms. Thus, somehow, the surveys in each field of specialization came to be completed. These on-site surveys shed light on various issues causing concern as well as problems requiring solutions, and afterward each member of staff was left to think about what could be done in his or her own specialist field and then to put ideas into practice. The university's practicalscience-based ideology calls on us always to prioritize solving problems at the location where they occur, and with this approach we were well equipped to work toward postdisaster recovery.

\subsubsection{Project Structure}

Based on the on-site surveys, we agreed that during the course of the East Japan Assistance Project our policy would be to act to resolve issues in response to requests for help from the disaster zones, rather than our researchers acting according to their own research interests. We structured the project as shown in Fig. 2.2 to enable us to respond to whatever requests we may receive from the areas affected by the disasters. 


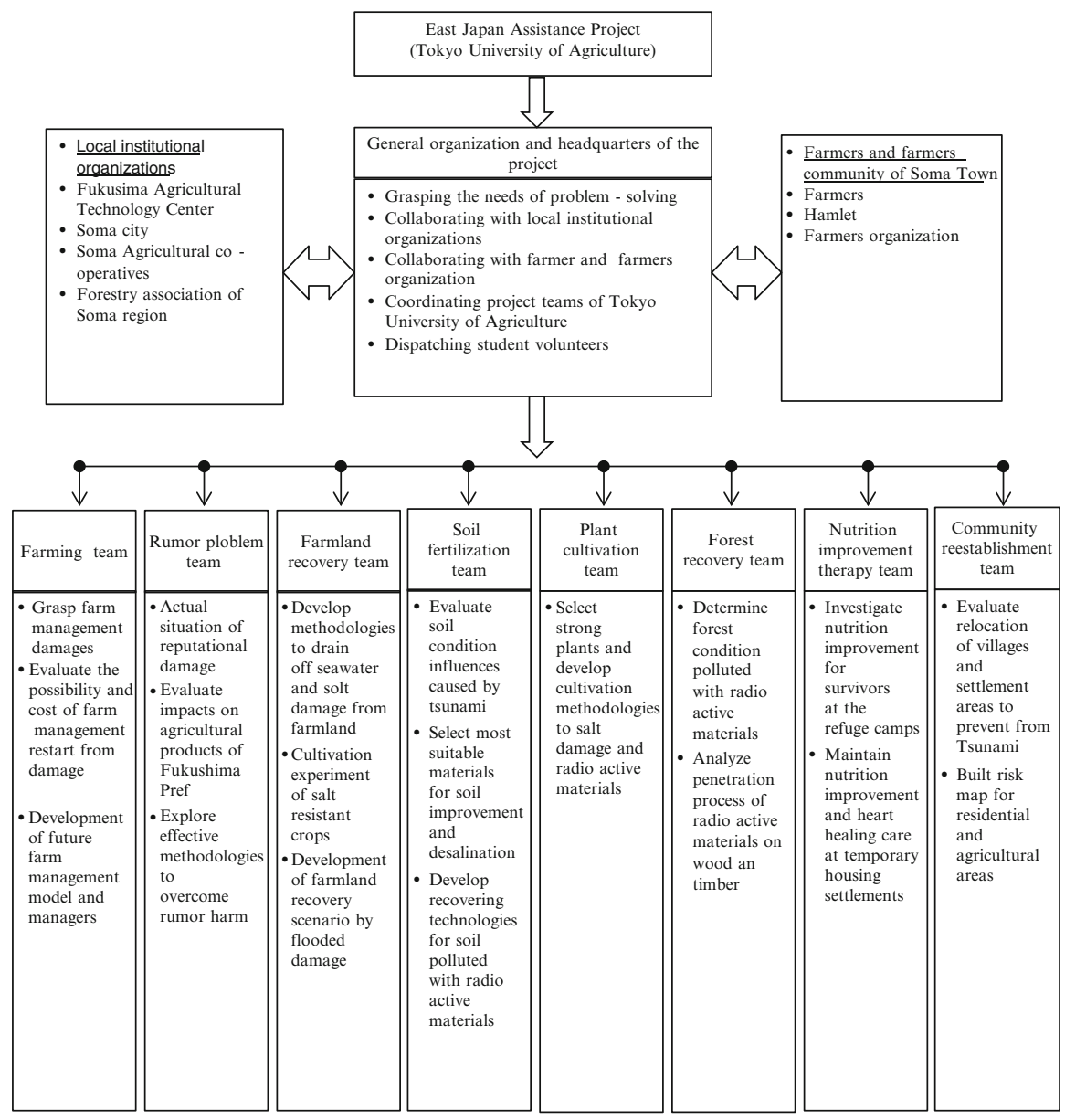

Fig. 2.2 Structure of the Tokyo University of Agriculture East Japan Assistance Project

\subsection{Start of Initiatives and Initial Research Outcomes}

\subsubsection{Student Volunteers}

Although they are not included in the project structure shown in Fig. 2.2, our student volunteers have played an extremely important role in the smooth implementation of our on-site initiatives and in establishing a framework for cooperating with the farmers affected by the disasters. While implementing the project we have responded to the farmers' requests, recruiting student volunteers specifically to help with reviving agriculture and sending them to the city of Soma for approximately 1 week, which is longer than most volunteers stay. The farmers asked us to send 


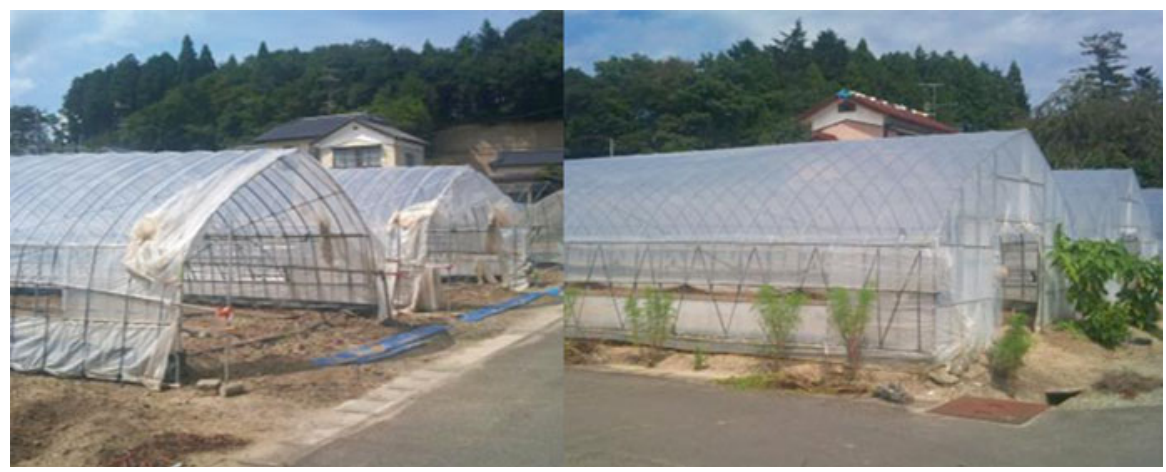

Fig. 2.3 Greenhouses recovered with the students' help (Photographs taken June 29, 2011)
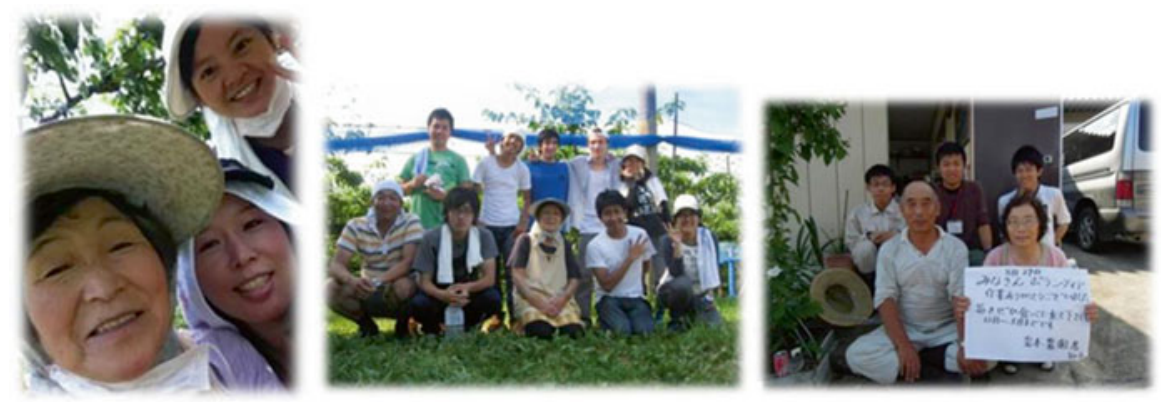

Fig. 2.4 Students earned the sincere gratitude of residents during their week in Soma

student volunteers to help them with a number of tasks that included recovering the strawberry greenhouses damaged by the tsunami, helping to grow strawberries so they could restart strawberry production, and undertaking crop thinning to help the nashi (Asian pear) farmers who were unable to manage the work alone because they had lost their homes and farming machinery in the tsunami. The university's international students have also taken part in these voluntary activities, working up a sweat through hard work in the fields, and making a major contribution to speeding up the recovery (Figs. 2.3 and 2.4). The student volunteers' efforts have become well known among Soma's farmers, and were instrumental in helping them to appreciate that the Tokyo University of Agriculture's project was not just another transitory research venture.

It would be fair to say that student volunteer activities such as these were the main reason why the university's project to support recovery in the city of Soma was warmly received by the farmers. 


\subsubsection{Farming Team}

After the project was launched on May 1, 2011, the farming team undertook activities broadly divided into three types, as follows:

1. Ascertaining the extent of agricultural damage and assessing desire to resume farming

2. Investigating factors determining motivation to resume farming and measures to assist farmers in starting again

3. Assessing the activities of existing agricultural reconstruction associations and investigating reconstruction models

The farming team addressed these issues mainly by researching the activities of farmers and communities affected by the disasters, as well as the activities of agricultural recovery associations. The research produced the following key outcomes with regard to the revival of farming (for further details, refer to Chap. 5).

\subsubsection{Investigating the Extent of Agricultural Damage and the Preconditions for Resumption of Farming}

The team demonstrated that the following measures would be important in enabling key farmers to resume their farming activities: (a) checking for radionuclides; (b) obtaining an assurance from the national government or Tokyo Electric Power Company (TEPCO) that they would compensate farmers by buying agricultural produce if radionuclides were detected and produce could not be sold; (c) recovering farmland, irrigation facilities, and other key infrastructure promptly; and (d) establishing frameworks for cooperating to achieve recovery in the various communities. The team's research also indicated that measures implemented by individual communities would play an important role in postdisaster agricultural revival.

Immediately after the disasters, many of the farmers showed a strong desire to restore their farms to the way they were; it was clear, therefore, that there was little prospect of introducing new types of farming or new crops. Furthermore, there were two factors of major importance in determining whether those farmers who had suffered tsunami damage wanted to return to farming: (1) the extent of tsunami damage to their farmland; and (2) the extent of tsunami damage to their farming machinery. The team identified the following four patterns (see Fig. 2.5) that characterized farmers' degree of motivation to resume farming according to the combination of major or minor damage to their land and machinery (Monma 2013).

Pattern 1: Desire to Resume Farming Weak: Both land and machinery sustained serious tsunami damage, and the farmer cannot restore them on his/her own. Key preconditions for recovery are reconstruction of farmland, irrigation facilities, and other infrastructure by the national government, as well as creation of a structure to share farming machinery within each community. Aid from the national government is also necessary. 


\begin{tabular}{|c|c|c|}
\hline & $\begin{array}{l}\text { Damage of } \\
\text { agricultural } \\
\text { machinery: } \\
\text { serious }\end{array}$ & $\begin{array}{c}\text { Damage of } \\
\text { agricultural } \\
\text { machinery: } \\
\text { slight }\end{array}$ \\
\hline $\begin{array}{c}\text { Tsunami damage } \\
\text { of farmland: } \\
\text { serious }\end{array}$ & $\begin{array}{l}\text { Desire to } \\
\text { resume } \\
\text { farming: } \\
\text { weak }\end{array}$ & $\begin{array}{l}\text { Desire to } \\
\text { resume } \\
\text { farming: } \\
\text { strong }\end{array}$ \\
\hline $\begin{array}{c}\text { Tsunami damage } \\
\text { of farmland: } \\
\text { slight }\end{array}$ & $\begin{array}{l}\text { Resumption } \\
\text { of farming: } \\
\text { dependent on } \\
\text { preconditions }\end{array}$ & $\begin{array}{l}\text { Desire to } \\
\text { resume } \\
\text { farming: } \\
\text { strong }\end{array}$ \\
\hline
\end{tabular}

Fig. 2.5 Level of desire and preconditioning for resumption of farming among farmers who suffered tsunami damage

Pattern 2: Desire to Resume Farming Strong: Despite serious tsunami damage to the farmer's land, his/her machinery was undamaged. In this case, provided that the national government recovers farmland, irrigation facilities, and other infrastructure, the farmer can resume farming on his/her own thereafter.

Pattern 3: Resumption of Farming Dependent on Preconditions: Even if the tsunami damage to their land was relatively slight, farmers whose machinery was destroyed or damaged are unable to replace the machinery on their own. Aid from the national government for purchasing new farming machinery is therefore essential. The form that subsequent farming takes will depend greatly on whether the government requires the farmers concerned to create an organization to share farming machinery or whether individual aid will be provided.

Pattern 4: Desire to Resume Farming Strong: Farmers who suffered minimal tsunami damage to their land or machinery demonstrated a desire to resume farming promptly. Provided that irrigation facilities and other infrastructure were not damaged, the individual farmer could deal with such tasks as removing the salt from his/ her land, but if radionuclides had accumulated, then decontamination would be essential. 


\title{
2.3.2.2 Agricultural Recovery Association Activities: Characteristics and Challenges
}

\author{
Purpose of the Research and Survey Method
}

Japan's Ministry of Agriculture, Forestry and Fisheries made it a policy objective to reconstruct local agriculture in the disaster-stricken areas and resume farming operations promptly. To that end, in May 2011 it created a scheme to offer financial aid to farmers affected by the disasters to help them start operating their farms again. The scheme pays 35,000 yen per 10 ares of paddy field to enable the farmers to restore their land to its previous condition to resume farming. Such restoration work might involve relatively straightforward removal of garbage and debris, repairing ridges between rice paddies and water conduits, or removing salt. This aid scheme is intended to encourage resumption of farming operations by enabling farmers to obtain income in return for undertaking farmland recovery work themselves. The financial aid is paid via agricultural recovery associations formed in each individual area, and payments are made to the individuals who make up the associations according to the role they play in recovery activities. Farmers in the city of Soma established 17 recovery associations, more than in other areas. Our project team investigated what activities were being undertaken by these agricultural recovery associations and identified the challenges they faced in pursuing their activities.

During November 12-21, 2011, the team conducted an interview-based survey, primarily targeting representatives of the agricultural recovery associations. During the survey the team started by establishing the features of the area covered by an association, the reasons behind the demarcation of that particular area, the events leading up to the association's establishment, and its main purposes. They then ascertained the extent of the damage sustained in the association's area according to three categories: farmland; irrigation facilities such as water supply and drainage channels, and ponds; and farming machinery.

\section{Overview of Survey Results}

Table 2.1 classifies the 17 agricultural recovery associations by defining three levels of damage, based on the damage sustained to farmland, irrigation facilities, and association members' farming machinery. The team used these classifications to identify the characteristics of individual associations' activities and the challenges they faced. The key features of the outcomes thus obtained were as follows (Batdelger et al. 2012).

First, the time and cost required for recovery differed entirely according to the extent of the damage. Any one-size-fits-all recovery measures that ignored the diversity in damage sustained would therefore be of little benefit. The extent of tsunami damage varied greatly from one district to another, and some types of recovery were impossible for farmers to handle on their own, making state funding 
Table 2.1 Characteristics of agricultural recovery association activities according to extent of damage

\begin{tabular}{|c|c|c|c|c|}
\hline \multicolumn{2}{|c|}{$\begin{array}{l}\text { Classification of the degree of } \\
\text { damage }\end{array}$} & \multirow{2}{*}{$\begin{array}{l}\mathrm{O}=1 \\
\text { Less than } \\
3 \text { weeks } \\
\text { (short term) }\end{array}$} & \multirow{2}{*}{$\begin{array}{l}\triangle=2 \\
\text { Less than } \\
3 \text { weeks (short } \\
\text { term) }\end{array}$} & \multirow{2}{*}{$\begin{array}{l}x=3 \\
\text { More than } 3 \text { weeks } \\
\text { (long term) }\end{array}$} \\
\hline $\begin{array}{l}\text { Damage of } \\
\text { farmland }\end{array}$ & Flooded period & & & \\
\hline & $\begin{array}{l}\text { Existence or } \\
\text { nonexistence of house } \\
\text { wreckage }\end{array}$ & None & $\begin{array}{l}\text { Deposited in } \\
\text { some farmlands }\end{array}$ & $\begin{array}{l}\text { Deposited in wide } \\
\text { area and huge } \\
\text { amounts }\end{array}$ \\
\hline & $\begin{array}{l}\text { Existence or } \\
\text { nonexistence of } \\
\text { wreckage of the } \\
\text { windbreak forest }\end{array}$ & None & None & $\begin{array}{l}\text { Deposited in huge } \\
\text { amounts }\end{array}$ \\
\hline & $\begin{array}{l}\text { The amount of } \\
\text { sediment by tsunami }\end{array}$ & $\begin{array}{l}\text { Thinly } \\
\text { partially } \\
\text { deposited }\end{array}$ & \begin{tabular}{|l} 
Thickly \\
deposited \\
partially
\end{tabular} & $\begin{array}{l}\text { Deposited in wide } \\
\text { area and huge } \\
\text { amounts }\end{array}$ \\
\hline \multicolumn{2}{|c|}{ Damage of irrigation facilities } & $\begin{array}{l}\text { No } \\
\text { problem }\end{array}$ & Self-recoverable & Own unrecoverable \\
\hline \multicolumn{2}{|c|}{ Damage of agricultural machinery } & None & $\begin{array}{l}\text { Fewer than half } \\
\text { of farmers lost } \\
\text { agricultural } \\
\text { machinery }\end{array}$ & $\begin{array}{l}\text { More than half of } \\
\text { farmers lost } \\
\text { agricultural machinery }\end{array}$ \\
\hline
\end{tabular}

Note: $\bigcirc$ small damage, $\triangle$ medium damage, $\times$ huge damage

essential: these included removal and replacement of topsoil covered in tsunami sediment mixed with fragments of glass or concrete, and replacement of farming machinery and equipment for farmers who had lost everything in the tsunami.

Second, the methods and time required to recover tsunami-damaged paddy fields varied greatly according to the extent of tsunami damage to the land and irrigation facilities. Included were the extent to which key farming amenities such as irrigation channels, bunds, and farm roads had been damaged; the amount of tsunami sediment and debris accumulated on the farmland; the extent to which cultivated soil had been lost, or had subsided; the length of time the fields were flooded with seawater; and the extent of damage to farming machinery and equipment.

Third, the biggest problem was how full-time farmers affected by the disasters would earn a living on a day-to-day basis when they had no source of income from a secondary occupation. The team realized there was some confusion regarding the use of the 35,000 yen per 10 areas of paddy field paid by the government for recovering of damaged farmland. They were able to confirm that in some cases the money was not necessarily used effectively to subsidize the living expenses of previously full-time farmers or to recover damaged farmland quickly.

Having identified problems such as these, the team made use of the information to provide feedback to the city authority, and as data to support the establishment of agricultural corporations. 


\subsubsection{Soil Fertilization Team}

Since the project started on May 1, 2011, the soil fertilization team has worked to assist the recover effort by taking immediate action to establish what techniques should be used for removing salt in farmland where tsunami damage was relatively slight. The first challenge was to test the soil in farmland where sediment had accumulated because of the ingress of seawater, to use the results to promptly come up with countermeasures, and to provide information about this process to the farmers affected by the disasters. The team's tests showed that although the salt concentration was high in the tsunami sediment accumulated on the farmland, the sediment had a greater capacity to retain fertilizer than soil itself and contained large amounts of exchangeable magnesium and potassium. Moreover, although the sediment was acid sulfate soil, it contained no harmful substances such as heavy metals or arsenic. Based on the results of this soil analysis, the soil fertilization team came up with the following plan for assisting with farmland recovery.

1. Avoid removing the layer of tsunami sediment, and instead mix it into the original topsoil

2. Remove salt using rainwater and by increasing the frequency of wet tillage before planting

3. Use steelmaking converter slag to help remove salt and counteract the acid sulfate in the soil

4. Implement measures to recover farmland in the following order: (1) tsunamidamaged strawberry greenhouses; (2) paddy fields containing no debris; (3) paddy fields containing debris or those under water for a long time

\subsubsection{Recovering the Strawberry Greenhouses}

The team recovered the strawberry greenhouses as follows (Fig. 2.6)

1. Removed salt from the soil via exposure to the rain from July through October

2. Replenished organic matter and encouraged soil aggregation by planting green manure (sorgo)

3. Planted cash crops such as spinach in the fall

4. Planted cash crops in spring 2012

5. Replanted strawberry seedlings in September 2012

\subsubsection{Method Used to Recover Tsunami-Damaged Paddy Fields}

Based on the results of tsunami sediment analysis, the team decided on the following recovering process for tsunami-damaged paddy fields and provided the farmers with relevant information. This recovery plan would later gain widespread acceptance as the Tokyo University of Agriculture Method (or the Soma Method). 


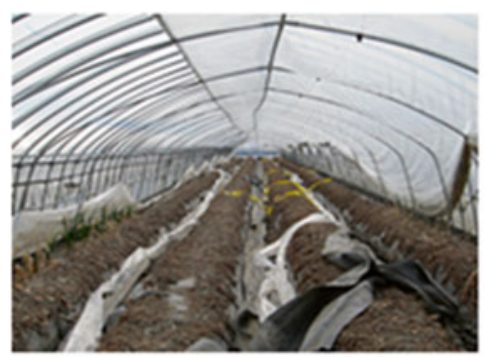

May 3

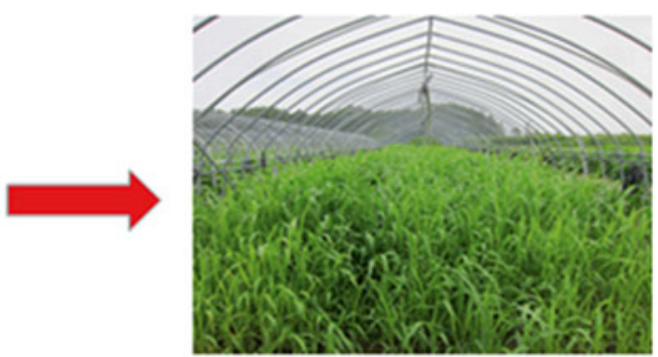

August 6
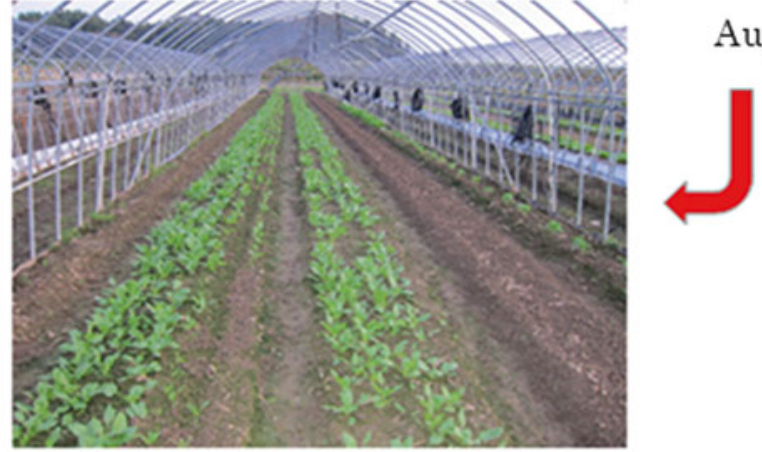

October 17

Fig. 2.6 Recovering the strawberry greenhouses (From soil fertilization team data)

1. Mix the layer of tsunami sediment into the paddy field's original topsoil

2. Improve water permeability by means of mole drainage

3. Apply $200 \mathrm{~kg} / 10$ ares of converter slag when the electrical conductivity of the mixed topsoil reaches approximately $0.5 \mathrm{mS} / \mathrm{cm}$

4. Remove salt by means of wet tillage, and plant paddy rice once irrigation and drainage facilities are restored

\subsubsection{Method Used to Recover Farmland Contaminated by Radioactivity}

In farmland where the level of radioactive contamination was low, the team recommended turning over or mixing in tsunami sediment or topsoil to reduce the cesium concentration and applying natural zeolite or converter slag to improve the soil, thereby inhibiting the absorption of radionuclide by crops. 


\subsubsection{Forest Recovery Team}

The forest recovery team is investigating ways to recovering forest areas by collecting data and analyzing the accumulation of radionuclide in forests and the penetration of cesium into trees. To that end, the team measured ambient radiation doses and collected samples for analysis, primarily targeting forests in the city of Minamisoma. The samples comprised cherry, oak, Japanese cedar, Japanese cypress, mulberry, and Japanese elk-horn cedar. The team is also experimenting with inhibiting absorption of radioactive cesium in Japanese cedar and poplar using a variety of metal ions $\left[\mathrm{K}^{+}\right.$(potassium ions), $\mathrm{Cs}^{+}$(stable cesium isotope ions), and $\mathrm{Ba}^{2+}$ (barium ions)].

The team is currently collecting data and analyzing how long it takes for cesium to penetrate the trunks and branches of trees to determine how to decontaminate trees that contain cesium (Fig. 2.7).
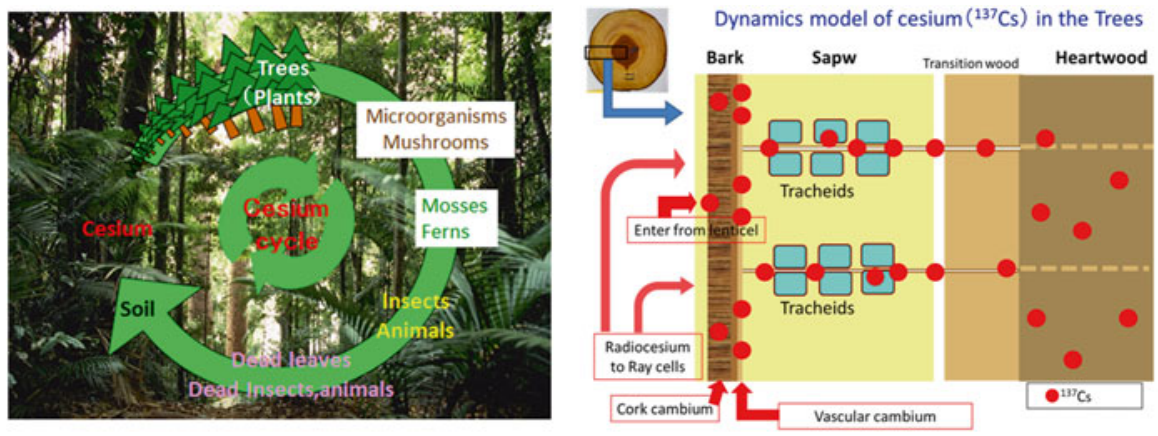

Flow of cesium-137 in the Trees

\begin{tabular}{|c|c|c|c|c|c|}
\hline \multirow{3}{*}{ Organization } & \multicolumn{5}{|c|}{ Distribution of cesium-137 (\%) } \\
\hline & \multicolumn{2}{|c|}{ Without treatment } & \multicolumn{2}{|c|}{ Fertilization of Call 4} & \multirow{2}{*}{ 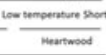 } \\
\hline & Normat & mentwood & Normal & Mentwosod & \\
\hline Leaves & 34.6 & 32.1 & +23.5 & +17.5 & +15.8 \\
\hline \multicolumn{6}{|l|}{ Tree stem } \\
\hline Tip & 4.7 & 4.5 & -2.9 & -3.6 & -3.5 \\
\hline Barks & 12.6 & 13.4 & +2.9 & +2.6 & +2.4 \\
\hline Cambium & 27.7 & 28.5 & -16.1 & -19.9 & -25.0 \\
\hline Xylem & 7.8 & 8.5 & -1.8 & +13.3 & +6.6 \\
\hline Roots & 12.7 & 13.0 & -5.7 & -4.9 & +3.8 \\
\hline
\end{tabular}

By potassium foliar spray, cesium transition to fruit was suppressed

Fruit of the persimmon

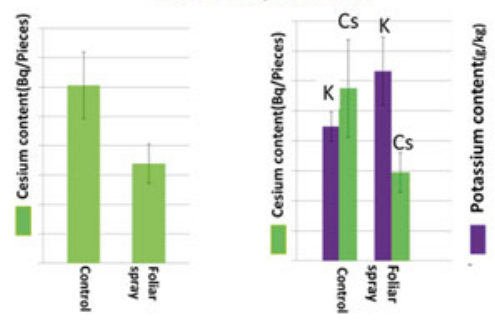

Fig. 2.7 The forest recovery team's findings (From forest recovery team data) 


\subsection{Success at the First Local Briefing Session Boosts Recovery Initiatives}

\subsubsection{The Importance of Local Briefing Sessions}

From the time when we were first planning the East Japan Assistance Project we emphasized the importance of holding on-site briefing sessions about the outcomes of our initiatives. The reasons for this were as follows:

1. To win support for our research outcomes by constantly providing feedback to the farmers and organizations involved and to identify new issues

2. To win more rapid support for our research outcomes by building a relationship of greater trust with the farmers

3. To ascertain any new needs for assistance with recovery

More importantly, however, when we were working on site helping with the recovery effort, we heard quite a few farmers complaining that plenty of researchers had already been there to conduct surveys, but hardly any of them ever got back to the farmers with the results. The farmers felt that they were being treated as nothing more than research subjects. Hearing the farmers say this impressed upon us how important it was to provide feedback to the farmers on the outcomes of our research.

\subsubsection{Anxiety and Success at the Local Briefing Session}

On November 28, 2011, one half year after we had commenced our initiatives to assist the city of Soma with its recovery, we held a briefing session in Soma to report on the progress of the recovery assistance project. As project leader, I was very anxious about holding such a meeting only 6 months after we had started. I wondered how many farmers and representatives of the local organizations involved would actually turn up. I was thinking that if hardly anybody came I would have to resign as project leader, and major changes would need to be made in the project itself.

In the event, however, so many people came (around 300 in total) that the meeting room was bursting at the seams. They listened with interest to our presentations on the progress of the project, and such an enthusiastic exchange of ideas ensued that we barely had enough time to cover everything. It was an extremely productive session that left me feeling relieved that we had not been doing the wrong thing for the past 6 months, but also acutely aware of our responsibilities going forward (Fig. 2.8). 


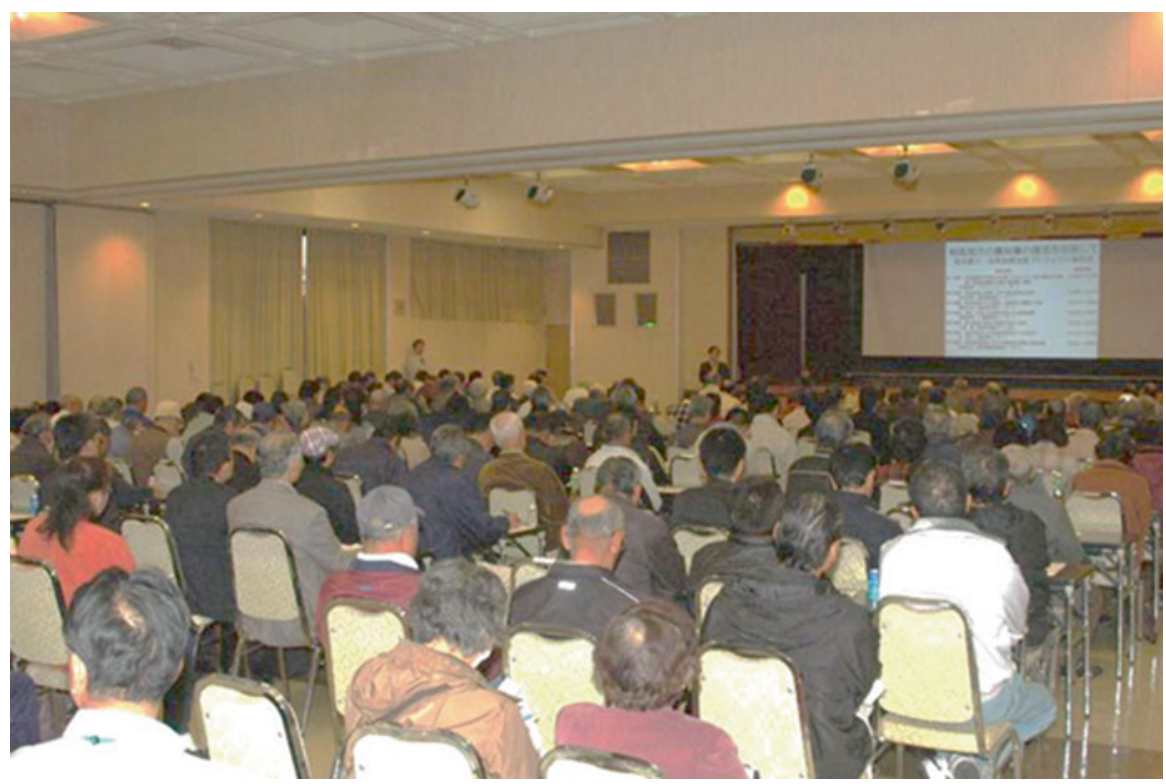

Fig. 2.8 Local farmers participated in the briefing session

\subsection{Fiscal 2012 Recovery Assistance Initiatives}

\subsubsection{Successful Rice Harvest from Seriously Tsunami- Damaged Paddy Fields}

To contribute to agricultural revival in tsunami-damaged areas, the soil fertilization team took the lead in conducting a trial to demonstrate the efficacy of using converter slag to help remove salt and counteract acid sulfate in soil as a means of effectively removing salt from tsunami-damaged paddy fields. They collaborated with farmers to plant paddy rice on 1.7 ha of paddy fields in Soma's Iwanoko district, which had sustained serious tsunami damage, and achieved a bigger-thanusual harvest of approximately $10 \mathrm{t}$. Moreover, every bag of the harvested rice passed the radioactivity tests conducted by the Fukushima Prefectural authorities, and our university's germanium semiconductor detector also detected no radioactivity. We named the rice Soma Reconstruction Rice, and marketed it actively to let the public know that the disaster zones were recovering (Fig. 2.9).

In fiscal 2013, we obtained a donation of $450 \mathrm{t}$ of converter slag from Nippon Steel \& Sumitomo Metal Corporation in order to use the Tokyo University of Agriculture Method to further boost the revival of paddy fields damaged by the tsunami. Together with $50 \mathrm{t}$ of converter slag bought by the university, this enabled us to conduct the same trial again on a 50-ha area of paddy fields. As of the date of writing, the rice plants are growing well. 


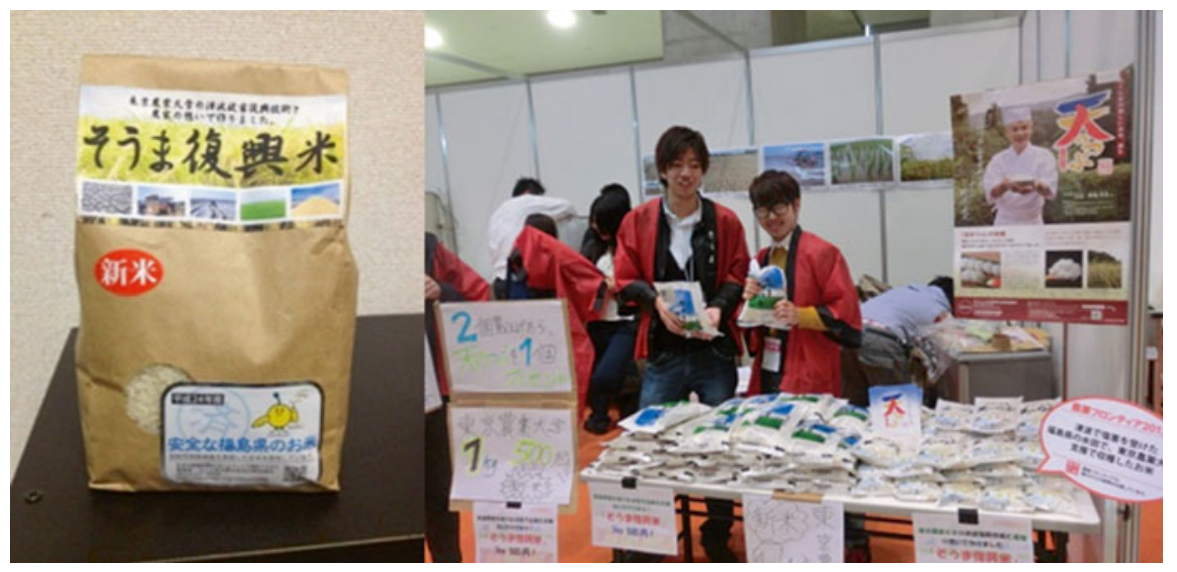

Fig. 2.9 A bag of Soma reconstruction rice (left $)$ and the rice on sale (right)

\subsubsection{Farming Assistance for Newly Established Agricultural Corporations}

The Soma City authority envisaged that key responsibility for postdisaster recovery would be assumed by agricultural corporations. It asked the university to help set up these corporations, and to assist with the corporations' subsequent farming activities. The university's farming and soil fertilization teams therefore took the lead in working to support Iitoyo Farm, the city of Soma's first agricultural corporation. Support offered by the farming team included (1) providing information about setting up the corporation; (2) researching the wishes of the local farmers to determine how farming activities should be developed once the corporation was established; and (3) making observational visits to localities leading the way in terms of collaboration between agriculture, commerce, and industry, and particularly in the vertical integration of agricultural production, processing, and sales and distribution. The soil fertilization team focused on the production of soybeans, Iitoyo Farm's main agricultural activity, using a 10-ha soybean field to analyze soil and provide advice on improving its quality.

\subsubsection{Developing a Monitoring System to Aid Recovery Following Radioactive Contamination}

In fiscal 2012 we launched a new initiative to hasten recovery in Soma's Tamano district, where radioactive contamination was severe, and to improve the efficiency of the recovery process. The farming team took responsibility for this initiative, aiming to establish a practicable monitoring system that would ensure the safety of 

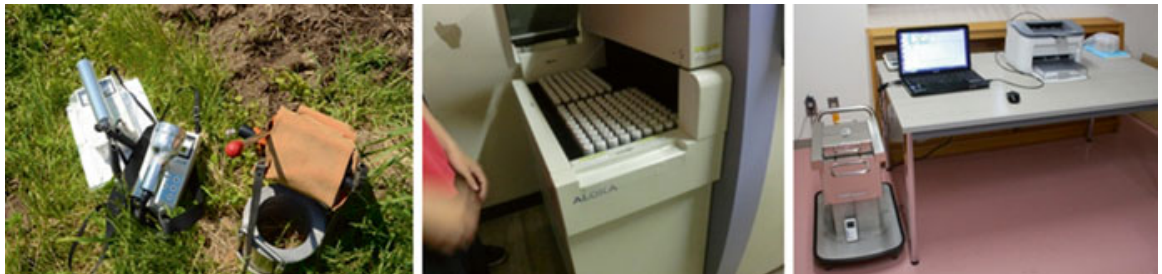

Fig. 2.10 Equipment used to measure and analyze radionuclides
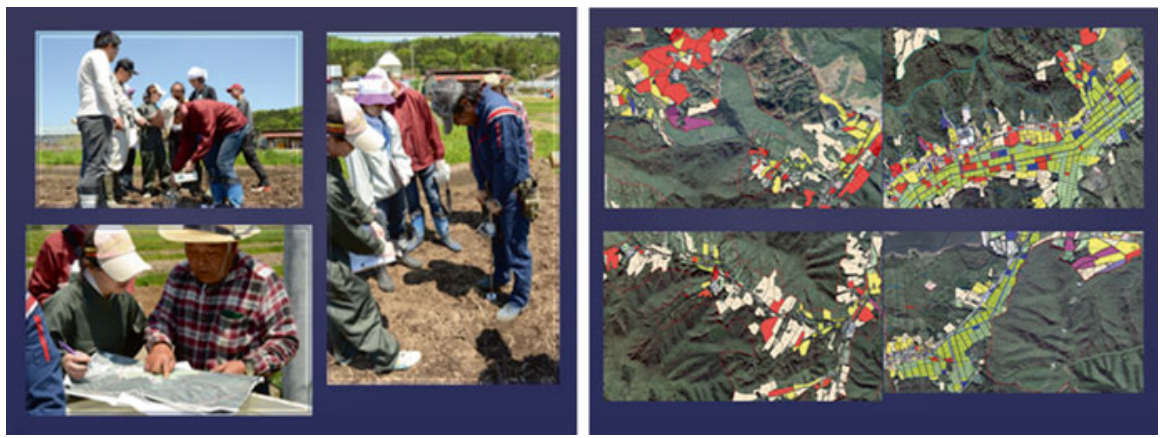

Fig. 2.11 Development of a system to monitor radionuclides: taking measurements (left), and mapping results (right)

all agricultural products produced in or shipped from contaminated areas. As a result, they are developing a monitoring system that enables the team to decide on appropriate decontamination measures and assess the efficacy of those measures by collecting and analyzing such key data as the ambient and soil radiation doses, the depth of the topsoil, and soil characteristics, one parcel of land at a time. They have already collected and analyzed data for the whole of Tamano, including its 646 paddy fields, non-paddy arable fields, pastures, and greenhouses, and have drawn up a decontamination plan (Figs. 2.10 and 2.11).

\subsubsection{Identifying and Counteracting Reputational Damage}

To understand the extent of damage to the reputation of agricultural produce within Fukushima Prefecture, and to find a way of overcoming that negative reputation, in December 2011 we surveyed 200 consumers at the Aizu Wakamatsu Farmers' Market. For the first year after the nuclear disaster, the national government had set a provisional limit for radioactivity in nondairy agricultural products of $500 \mathrm{~Bq} / \mathrm{kg}$ or less, and in April 2012 it set a new, reduced limit of $100 \mathrm{~Bq} / \mathrm{kg}$ or less. During the survey, as many as 40-50\% of respondents replied that they could not decide 
whether these limits were safe, and because the meanings of the terms used to describe these limits had not been explained clearly to consumers, they had no means of judging their safety. In addition, we found that they were unsure about the reliability of the actual figures used for the limits. Although reducing the limit from $500 \mathrm{~Bq} / \mathrm{kg}$ to $100 \mathrm{~Bq} / \mathrm{kg}$ could no doubt make consumers feel safer to a certain extent, still almost one in four of our respondents replied that they did not feel reassured by the new limit. This response indicated that it was difficult to eradicate consumers' anxiety just by reducing the limit. It was clear, therefore, that at the very least agricultural products needed to obtain an "ND" (not detectable) rating in tests if consumers' peace of mind was to be assured (Monma 2014 Fig. 2.12).

\subsubsection{Investigating Methods for Inhibiting Absorption of Radionuclide}

The soil fertilization team is working both to recover farmland damaged by the tsunami and to develop and trial practicable methods for decontaminating farmland contaminated with radionuclide. It is playing an important role in initiatives to develop decontamination methods through its analysis of soil fertilization. One such initiative targets the paddy fields in Minamisoma, where planting of paddy rice for consumption is prohibited; in another case the team is working with the University of Tokyo and Fukushima University to develop an efficient means of decontaminating paddy fields in the city of Date (Fig. 2.13).

\subsubsection{Forest Reconstruction Initiatives}

The forest reconstruction team is pursuing research to help establish measures for counteracting radioactive contamination in forests. To this end, it is investigating how radionuclides enter trees via their leaves, bark, and roots to contaminate the wood itself. Specifically, this entailed felling approximately 30 trees, primarily Japanese cedar and cypress, and cutting the wood into cross sections to analyze the accumulation of radionuclide over time according to each annual growth ring (Fig. 2.14). This plan enabled the team to ascertain that the highest levels of radioactive cesium were found in the outer bark, but that cesium had also penetrated to the wood inside.

When the team released the results of their analysis to the press on February 1, 2012, the public received the news with some alarm. Currently, the team is still analyzing in detail the routes by which cesium penetrates the trees' interior. It is also conducting empirical research into the efficacy of specific decontamination methods such as aerial spraying of potassium and washing contaminated wood with water. 

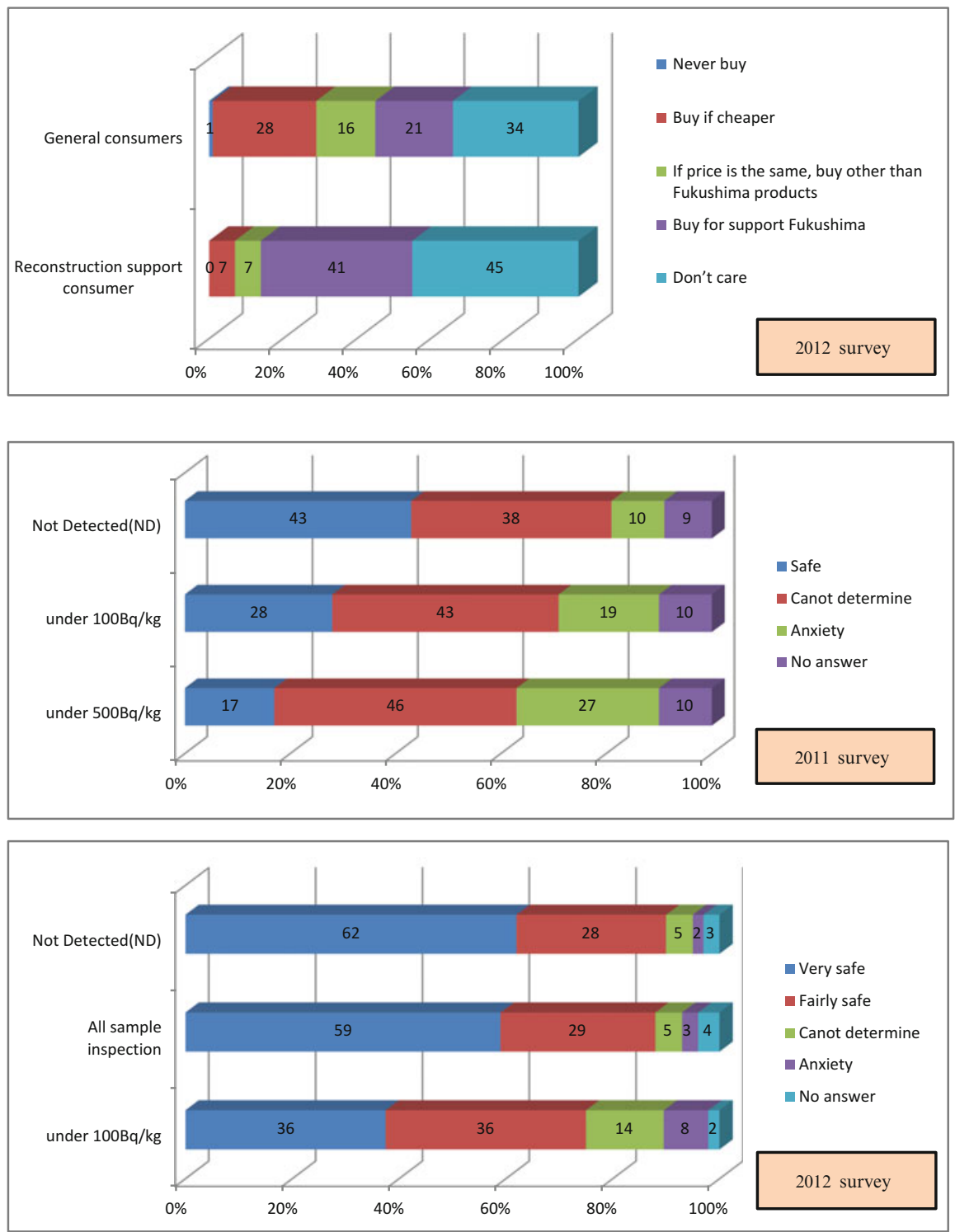

Fig. 2.12 Consumer willingness to purchase agricultural products from Fukushima and consumer sentiment toward test method and radioactive content limits

\subsubsection{The Fiscal 2012 Local Briefing Sessions}

The local briefing sessions on the fiscal 2012 outcomes of the East Japan Assistance Project's initiatives were held on February 23 and 24, 2013. The two sessions were held in separate venues, one in the area damaged by the tsunami, and the other in the area that had suffered radioactive contamination. 

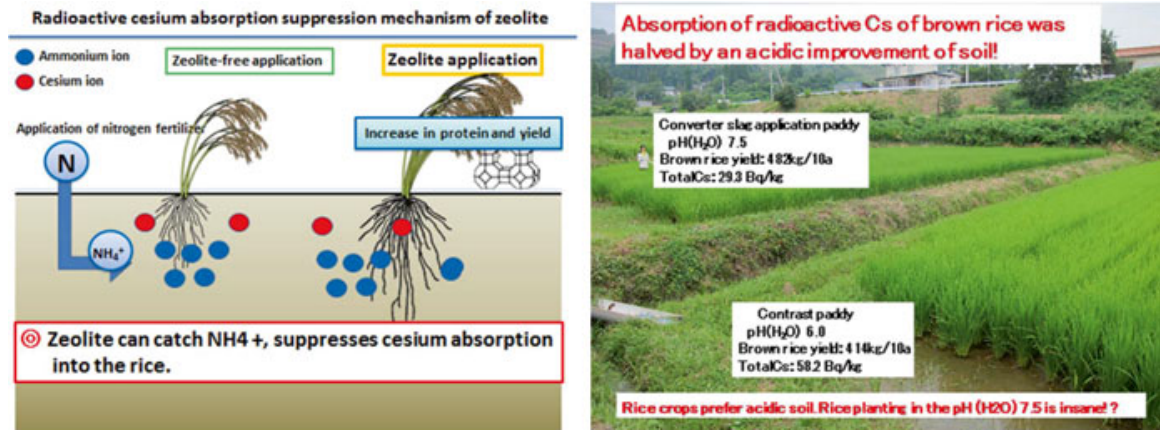

Fig. 2.13 Technology to inhibit absorption of radioactive cesium (left), and the technology under trial (right) (From soil fertilization team data provided)
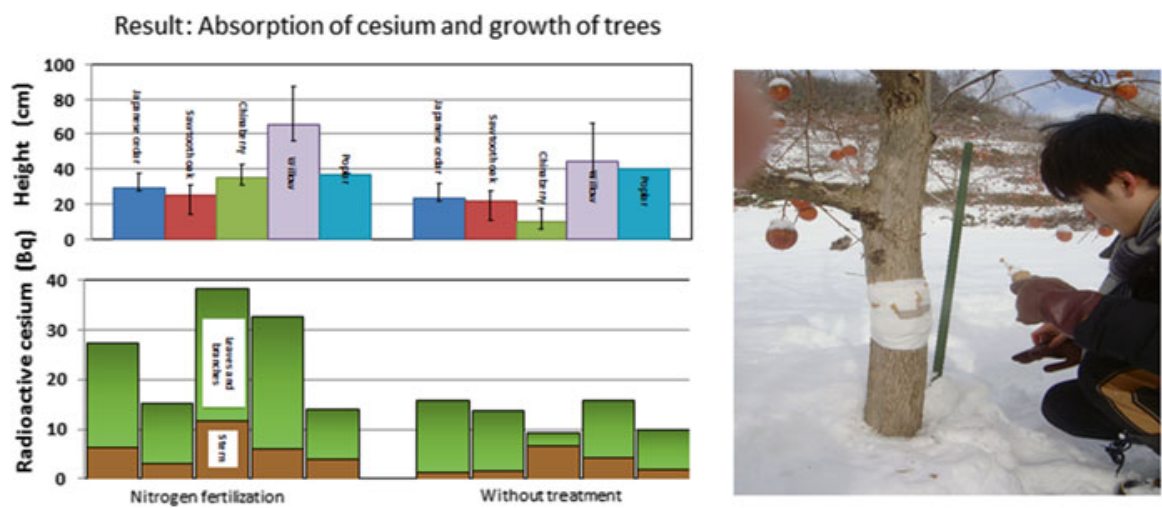

Fig. 2.14 Tree growth and cesium absorption (left) and decontamination of a persimmon tree (right) (From forest reconstruction team data provided)

On February 23 approximately 200 people attended, leaving us in no doubt as to the residents' high expectations of the Tokyo University of Agriculture's efforts to help with recovery. First, our researchers addressed the initiatives to assist with reconstruction in tsunami-damaged areas, giving a presentation about the success achieved using the Tokyo University of Agriculture Method to revive seriously damaged paddy fields. Their success story provided all those present with strong motivation to plant a greater area in fiscal 2013. The residents were also interested to hear a presentation about the problematic issue of damage sustained by forests, and the associated efforts to decontaminate it. Meanwhile, another presentation reported the results of a survey on local residents' opinions and expectations with regard to the newly established agricultural corporations. It described generally high hopes that the area's agriculture could continue and thrive if new entities and individuals could be organized to take over, and indicated that rapid integration of farmland was likely to be possible. Thus the audience was left feeling hopeful with 

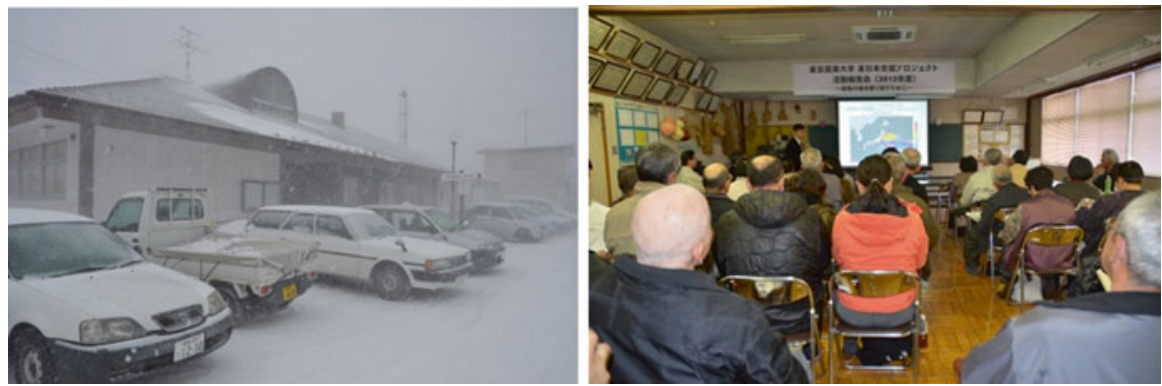

Fig. 2.15 Briefing session held in Tamano in heavy snow

regard to new developments in Soma's agriculture. Then, moving on to the issue of reputational damage, the researchers presented the results of their surveys on consumers' opinions of, and willingness to buy, agricultural produce from Fukushima Prefecture, and on the efficacy of testing for radionuclide in terms of reducing the negative reputation. They emphasized the importance of endeavoring to make absolutely sure that no contaminated agricultural produce is shipped from Fukushima and were able to win the audience's support in this regard.

On February 24 we were scheduled to hold our first briefing in Tamano, where the biggest problem was radioactive contamination. Unfortunately, however, the temperature had dropped and it snowed heavily, so we did not expect many people to come. A low turnout seemed likely also because few people had attended most of our previous information sessions about radioactivity-related measures. But by the time the session was to start, the Tamano community center venue was packed with nearly 80 local residents (Fig. 2.15). It was clear to us, therefore, that the local people were very keen to revive agriculture in their area once decontamination was completed. Our researchers' presentations covered technology to inhibit the absorption of radioactive cesium in paddy fields, methods for decontaminating forests, radioactive contamination in the Tamano district and the results achieved using the monitoring system, as well as the situation with regard to reputational damage and measures for overcoming the negative reputation. The discussion that followed became a spirited debate between the audience and the presenters, as members of the audience asked question after question about how agricultural production could take place in future by controlling radionuclide. The snow fell rapidly as the session proceeded, reaching nearly $20 \mathrm{~cm}$ in depth, but everybody stayed until the end, and it turned out to be a very worthwhile briefing.

\subsection{Course of Action in Fiscal 2013}

The key initiatives during fiscal 2013 (April 2013 to March 2014) are as follows.

1. Work to expand our recovery activities from individual points on the map to wider geographic areas. To this end, we used the Tokyo University of Agriculture 
Method to plant paddy rice in 50 ha of paddy fields that had been seriously damaged by the tsunami, and planted soybeans in the 1.7 ha of paddy field that was used for producing rice last year. We plan to ensure the safety of the rice and soybeans harvested from these fields by testing for radionuclides; all the rice confirmed as safe will be actively marketed as Soma Revival Rice.

2. Consider new ways of using paddy fields that were damaged so seriously that reconstruction is impossible and investigate models for the area's agriculture accordingly.

3. Develop and trial technology to inhibit the absorption of radionuclide in paddy fields where radioactive contamination is severe (continue joint research in the city of Date with the University of Tokyo and Fukushima University).

4. Investigate the mechanisms whereby radionuclides move through forests and trees. Use this research to develop and trial technology for eliminating radioactive cesium accumulated in persimmon trees with a view to resuming local production of partially dried persimmons. Meanwhile, amass scientific knowledge to be used in developing a variety of potentially effective methods for decontaminating the forests, and conduct on-site trials of such methods.

5. Finish developing the system for monitoring radionuclides in the city of Soma's Tamano district, and use the final version as the basis for developing and trialing a new system to control radiation levels in both soil and crops.

6. Assist with the activities of Soma's newly established agricultural corporations (by identifying ways for the corporations to collaborate with other local farmers and manage their businesses, and by helping with efforts to vertically integrate agricultural production, processing, and sales and distribution).

7. Assess how the area's agriculture might develop in future, and recommend a vision for that agriculture centered on new entities and individuals, along with a suitable governmental policy structure to provide support.

Open Access This chapter is distributed under the terms of the Creative Commons Attribution Noncommercial License, which permits any noncommercial use, distribution, and reproduction in any medium, provided the original author(s) and source are credited.

\section{References}

Batdelger N, Yamada T, Suzumura G, Sibuya Y, Lurhathaiopath P, Monma T (2012) Actual situation and evaluation of reconstruction union activities in tsunami damaged area. J Rural Econ (Special Issue 2012):192-198 (in Japanese)

Monma T (2013) Efforts of the reconstruction from Great East Japan earthquake by Tokyo University of Agriculture and Scenario of farming reconstruction. J Food Agric Environ 11:2225 (in Japanese)

Monma T (2014) Research trends of radioactive contamination influence on agriculture and food consumption behavior. J Rural Econ 85(1):16-27 (in Japanese) 